\title{
A PERCEPÇÃO DE \\ UNIVERSITÁRIOS SOBRE OS TRANSGÊNICOS: ESTUDO DE CASO EM UMA INSTITUIÇÃO PÚBLICA EM CUIABÁ (MT)
}

\author{
Cristovão Leite Bezerra Segundo ${ }^{1}$ \\ Sandra Mariotto ${ }^{2}$ \\ Nadja Gomes Machado ${ }^{3}$
}

Resumo: Os transgênicos são organismos que tiveram uma sequência de DNA de outro organismo inserido em seu genoma a fim de adquirir certas características comuns a estes. Eles podem ser utilizados na produção de animais ou vegetais. O cultivo e comercialização de transgênicos no Brasil, apesar de ser liberada pela CTNBio, gera posicionamentos contrários, evocando-se o Princípio da Precaução. Neste contexto, este estudo teve como objetivo conhecer a percepção de universitários dos cursos de Tecnologia em Gestão Ambiental e Engenharia de Alimentos sobre os transgênicos no Campus Cuiabá - Bela Vista do IFMT. A pesquisa foi realizada por aplicação de questionário aos universitários dos referidos cursos em 2012. Os pesquisados demonstraram ter conhecimento sobre 0 assunto, mas são conservadores quanto ao consumo de alimentos transgênicos. Eles revelaram que as principais fontes de informação são as mídias (impressa, TV e internet), seguidas pelas instituições de ensino. Embora, a maior fonte de informação tenha sido os veículos de informação, os pesquisados disseram que essas informações são menos confiáveis do que as oriundas das instituições de ensino. Este fato revela a responsabilidade das instituições de ensino de esclarecer a sociedade sobre temas polêmicos como os transgênicos.

Palavras-chave: Engenharia Genética; Impactos Ambientais; Saúde Humana. Educação Ambiental.

1 Instituto Federal de Mato Grosso. E-mail: einstein@gmail.com

2 Instituto Federal de Mato Grosso. E-mail: sandra.mariotto@blv.ifmt.edu.br

${ }^{3}$ Instituto Federal de Mato Grosso. E-mail: nadja.machado@blv.ifmt.edu.br

Revbea, São Paulo, V. 11, No 5: 30-38, 2016. 


\section{Introdução}

Os transgênicos ou Organismos Geneticamente Modificados (OGMs) são organismos que tiveram uma sequência de DNA, parcial ou total, de outro organismo introduzida em seu genoma, a fim de adquirir certas características comuns a este (CTNBio, 2015). Os rápidos avanços no campo da manipulação das componentes fundamentais dos seres vivos tornam os cientistas ainda mais responsáveis pela vida e saúde da população (GIULIANI, 2000). Atualmente, a maior parcela da produção de transgênicos está voltada para a produção de alimentos. O consumo de alimentos com traços de transgênicos em nosso país pode ser considerado alto, levando-se em conta a utilização da soja na composição de muitos alimentos industrializados (CI SOJA, 2012), e que a soja brasileira é em grande parte transgênica.

Pesquisas brasileiras apontam que existe uma grande dúvida da população sobre os transgênicos, uma vez que a população se considera mal informada pelos meios de comunicação (FURNIVAL; PINHEIRO, 2008). Essa falta de informação, ou sua incompletude, podem levar a população a ter uma postura de dúvida ou rejeição aos transgênicos. Porém, as pesquisas realizadas sobre OGMs ainda não conseguiram comprovar se são seguros ou se apresentam riscos consideráveis, o que torna a discussão polarizada. Geralmente, a discussão polarizada pouco tem contribuído para a formação de opinião, visto que ocorrem somente ataque e defesa das oposições, sem que se busque o consenso e esclarecimento fundamentado em bases científicas.

Destaca-se que, os fundamentos existem tanto para serem liberados quanto para serem proibidos, como é possível perceber no posicionamento de algumas Organizações Não-Governamentais (ONGs) e, em outro extremo, por grandes empresas desenvolvedoras dessa tecnologia ou instituições relacionadas com esses produtos. No meio científico e acadêmico, há aqueles que são a favor e os que são contra, mas as evidências científicas ainda não foram suficientes para impedir que estes produtos fossem liberados e/ou comercializados.

No Brasil, a Comissão Técnica Nacional de Biossegurança (CTNBio), que é responsável por analisar os riscos dos OGMs e emitir parecer para sua liberação ou não, liberou o plantio e a comercialização de soja, milho e algodão transgênicos no território brasileiro. Este fato encontra resistência, principalmente de ONGs e de instituições como o Instituto de Defesa do Consumidor (IDEC) e o Instituto Brasileiro de Meio Ambiente e dos Recursos Naturais Renováveis (IBAMA) (COLLI, 2011).

As universidades muitas vezes são consultadas por solicitação da CTNBio quanto a informações sobre os transgênicos (COLLI, 2011), o que demonstra a importância das instituições de ensino e pesquisa. Assim, instituições como o Instituto Federal de Mato Grosso (IFMT) devem dar subsídios à formação de seus estudantes, de forma que tenham acesso à informação suficiente sobre 0 assunto. Esse estudo teve como objetivo 
conhecer a percepção de universitários dos cursos de graduação em Tecnologia em Gestão Ambiental e Engenharia de Alimentos sobre os transgênicos no Campus Cuiabá - Bela Vista do IFMT, em Cuiabá (MT).

\section{Metodologia}

A pesquisa foi realizada com 71 alunos de graduação em Tecnologia em Gestão Ambiental e Engenharia de Alimentos, do primeiro e do último semestre no Campus Cuiabá - Bela Vista do Instituto Federal de Mato Grosso (IFMT), Cuiabá (MT). O questionário foi pré-concebido para atender o objetivo do estudo. Os questionários foram aplicados em horário de aula, em outubro de 2012, a todos os alunos presentes, que aceitassem participar da pesquisa. $O$ questionário continha um Termo de Consentimento Livre e Esclarecido, onde se esclarecia ao participante os objetivos da pesquisa e este autorizava a utilização dos dados por ele fornecidos. Os dados foram tabulados com a utilização em planilha, e posteriormente foi realizada a filtragem e análise dos dados.

\section{Resultados e Discussão}

Ao todo, 71 estudantes responderam o questionário, dos quais $64 \%$ são do curso de Tecnologia em Gestão Ambiental e 36\% do curso de Engenharia de Alimentos. Tal diferença pode ser explicada pelo fato do curso de Tecnologia em Gestão Ambiental ocorrer nos períodos matutino e noturno, enquanto que o de Engenharia de Alimentos, em período integral, havendo assim apenas uma turma por semestre. A maioria deles cursava o primeiro semestre e $75 \%$ ainda não havia feito outro curso de nível superior (Figura 1).

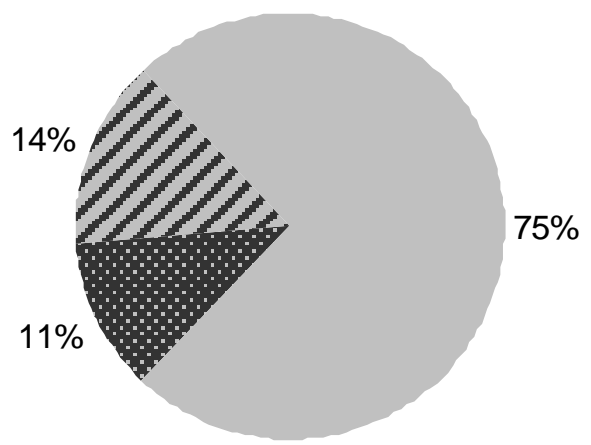

* Já concluíram outro curso de nível superior

$75 \%$ Estão cursando outro curso de nível superior

Estão cursando curso superior pela primeira vez

Figura 1: Situação dos discentes dos cursos de Tecnologia em Gestão Ambiental e Engenharia de Alimentos do Campus Cuiabá - Bela Vista do IFMT em 2012, com relação a outro curso de nível superior do IFMT.

A maioria é do sexo feminino $(73,73 \%)$ e a faixa etária mais frequente é de 20 a 29 anos (Figura 2). 


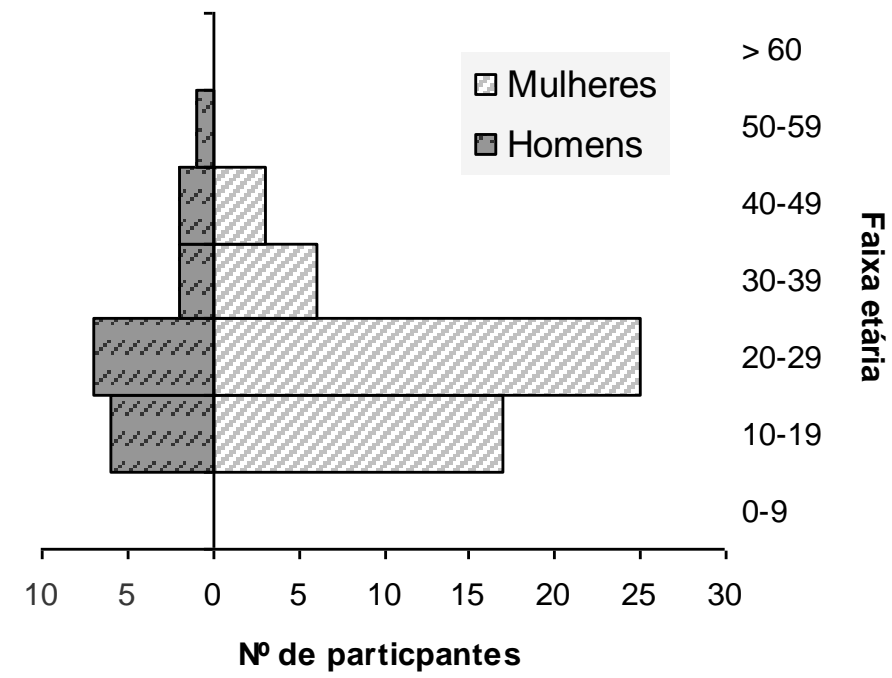

Figura 2: Participação por faixa etária dos discentes dos cursos de Tecnologia em Gestão Ambiental e Engenharia de Alimentos do Campus Cuiabá - Bela Vista do IFMT em 2012.

A maioria cursa o primeiro semestre (Figura 3), que pode ser explicado pela desistência que há no decorrer dos cursos.

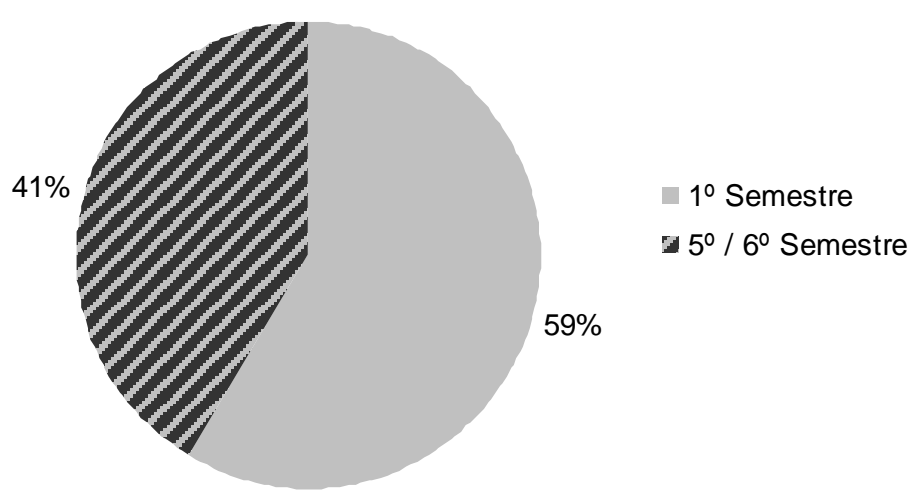

Figura 3: Participação por semestre dos cursos de Tecnologia em Gestão Ambiental e Engenharia de Alimentos do Campus Cuiabá - Bela Vista do IFMT em 2012.

Os participantes demonstraram ter conhecimento a respeito dos transgênicos e de seu efeito no meio ambiente e à saúde humana. A maioria $(92,75 \%)$ respondeu de forma correta, quando questionados sobre o que são os transgênicos. Na questão sobre os efeitos do plantio no meio ambiente, $58,57 \%$ responderam que ainda não se conhece bem as consequências ao meio ambiente. Quanto aos efeitos destes alimentos à saúde humana, 62,86\% concordam que ainda não se tem pesquisas de longo prazo para se afirmar que os transgênicos causam problemas de saúde. Informação semelhante foi encontrada por Guivant (2006) ao destacar em pesquisa na Nova Zelândia que grande parte dos consumidores acredita que ninguém ainda tenha informações 
precisas sobre os transgênicos. Nos Grupos Focais realizados por Furnival e Pinheiro (2008), os participantes se mostraram insatisfeitos em não ser possível dimensionar os efeitos do uso dos transgênicos.

Quanto à presença dos transgênicos na alimentação, a maioria revelou ter consciência de que já consumiram, e demonstraram que tem capacidade de identificar um produto de origem transgênica; e 64,29\% responderam de forma correta, que o percentual de soja geneticamente modificada produzida em nosso estado está entre 60 e $85 \%$. Esta informação é importante tendo em vista que, grande parte dos alimentos industrializados consumidos contém soja. Ainda, $61 \%$ dos participantes afirmaram já ter consumido algum produto que contém transgênico, o que foi corroborado por estudo realizado por (GUIVANT, 2006) na Ásia em que o mesmo percentual foi encontrado sobre o conhecimento da presença de alimentos transgênicos em sua alimentação. Diferentemente do encontrado neste estudo, pesquisas nos Estados Unidos revelaram que apenas $14 \%$ dos participantes acreditavam que mais de metade dos alimentos consumidos continham transgênicos (GUIVANT, 2006).

Ressalta-se que, $57,75 \%$ dos participantes afirmaram identificar de forma correta estes produtos, pelo símbolo característico presente na embalagem. $O$ fato de saberem identificar tem grande relevância, tendo em vista que grande parte das pesquisas revela o interesse do consumidor em ter direito à escolha no momento da compra. A pesquisa realizada pelo Greenpeace (2003) demonstrou que $92 \%$ dos entrevistados pensa que a informação deve estar contida no rótulo dos alimentos que contem transgênicos. Furnival e Pinheiro (2008) também identificaram nos Grupos Focais pesquisados a insatisfação dos consumidores em não terem acesso a essa informação.

Apesar de terem conhecimento a respeito do assunto e saberem que ainda não há comprovação científica de que sejam prejudiciais à saúde ou ao meio ambiente, a maioria dos pesquisados neste estudo, caso pudesse escolher, daria preferência a produtos de origem tradicional, independente do preço $(43,66 \%)$ ou só escolheria transgênico se este fosse mais barato $(22,54 \%)$. Em pesquisas realizadas em todos os estados brasileiros entre 2001 e 2003, o Greenpeace (2003) identificou rejeição por parte dos consumidores, uma vez que, $74 \%$ dos consumidores escolheriam um alimento não transgênico, caso pudessem escolher.

Em outra pesquisa realizada pelo Greenpeace sobre transgênicos (2003), 24\% dos participantes foram favoráveis aos alimentos transgênicos, e após a veiculação de comercial sobre a desmistificação dos transgênicos, a aceitação subiu para $45 \%$. Na Nova Zelândia, a aceitação aumenta quando há o benefício de um menor preço do produto (GUIVANT, 2006). Nas pesquisas internacionais realizadas pela Environics International em 2000 e 2001 é perceptível a diferença na aceitação dos alimentos transgênicos em países da Europa e em países americanos como Estados Unidos e Brasil (GUIVANT, 2006). Os europeus rejeitam mais os alimentos geneticamente modificados, enquanto que os norte-americanos, principalmente os dos Estados Unidos tem Revbea, São Paulo, V. 11, № 5: 30-38, 2016. 
maior aceitação. Esta informação é confirmada por diversas pesquisas Europeias em que a maioria rejeita os alimentos transgênicos mesmo sendo favoráveis ao uso da transgenia na criação de medicamentos, por exemplo (GUIVANT, 2006).

A informação sobre os transgênicos disponibilizada na mídia é considerada pela maioria dos pesquisados $(73,24 \%)$ como insuficientes para que possam decidir com segurança num momento de escolha, apesar de terem demonstrado ter conhecimento do assunto. Furnival e Pinheiro (2008) também identificaram nos Grupos Focais a insatisfação com a pouca informação e de baixa qualidade, associando-a aos relatos dos participantes que associaram os transgênicos a imagens de ficção científica. Na pesquisa desses autores, os participantes demonstraram ter conhecimento sobre o assunto, mas ainda consideram as informações disponibilizadas insuficientes.

De acordo com as respostas, os meios que consideram ter recebido mais informação a respeito dos transgênicos pela TV (24,64\%), pelas mídias impressas e internet (24,64\%), seguida pela escola (23,19\%) (Figura 4). Furnival e Pinheiro (2008) também encontraram que os participantes percebem a mídia como grande difusora de informação, mas que não fornecem informações claras sobre o assunto. A mesma pesquisa aponta a comunidade científica como principal fonte de informação potencialmente confiável, o que revela a importância das instituições de ensino e pesquisa na formação de opinião e difusão de conhecimento. O considerável empate entre a escola e os meios de comunicação reveladas nesta pesquisa, pode apontar para a importância da instituição de ensino e das discussões sobre este assunto nestes locais para a produção de conhecimento confiável e difusão de informação para a população.

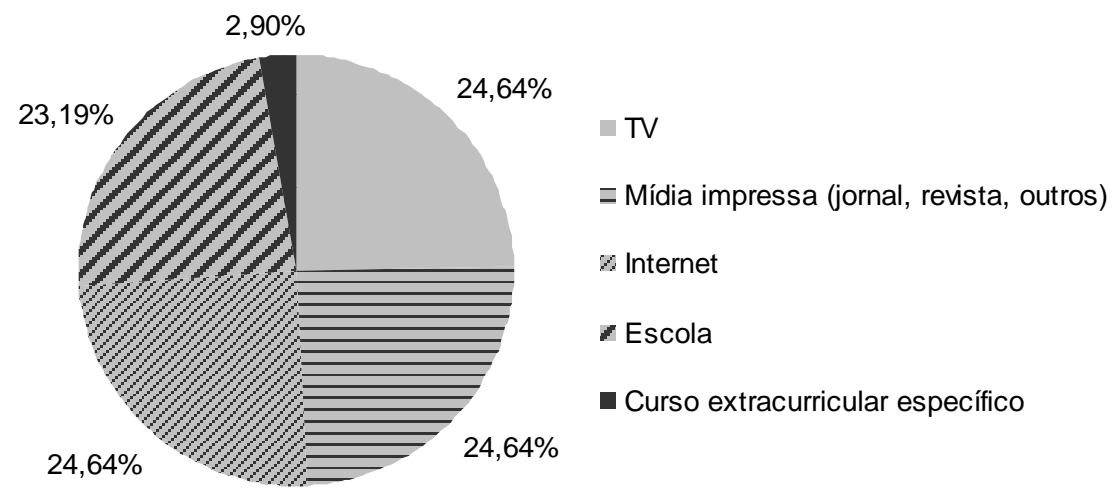

Figura 4: Meios de acesso à informação sobre transgênicos por alunos do curso de Tecnologia em Gestão Ambiental e Engenharia de Alimentos do Campus Cuiabá - Bela Vista do IFMT em 2012.

Os participantes (67\%) afirmaram que o tema "transgênicos" foi pelo menos comentado em aula. Aqueles que afirmaram não ter tido informação nas 
aulas na instituição pode ser pelo motivo de estarem ainda no primeiro semestre e não terem tido o assunto nas disciplinas. Guivant (2006) entende a falta de problematização no espaço acadêmico como fator que contribui para a pouca quantidade de pesquisas de opinião pública sobre os transgênicos, como ocorre atualmente no país. Todos os pesquisados acham importante $(64,97 \%)$, ou importantíssimo (38,03\%) discutir o assunto nas aulas. Esta unanimidade, da importância de ter o assunto tratado nas instituições de ensino, pode refletir a confiança depositada nessas instituições formadoras de opinião e local próprio para a discussão de assuntos como este. Demonstra ainda, uma possível insegurança nas informações disponíveis nos veículos de comunicação.

Embora, as informações mais acessíveis e menos confiáveis sejam através dos veículos de comunicação (FURNIVAL; PINHEIRO, 2006; LABJOR, 2002 e 2003), os participantes consideram os cientistas, as ONGs de defesa do meio ambiente, e as instituições de ensino as fontes mais confiáveis sobre os transgênicos (GUIVANT, 2008). Enquanto o número de consumidores bem informados sobre biotecnologia não for maioria esmagadora será importante continuar as pesquisas de opinião e divulgação sobre alimentos geneticamente modificados (FOOD INSIGHT, 2006). Portanto, fica evidente a responsabilidade das instituições de ensino de esclarecer a sociedade sobre temas polêmicos como os transgênicos.

\section{Conclusões}

Os participantes desse estudo são universitários em Tecnologia em Gestão Ambiental e Engenharia de Alimentos, portanto já concluíram o Ensino Médio, e estão em busca de inserção no mercado de trabalho. No decorrer da discussão e por meio das respostas obtidas, ficou evidente que os futuros profissionais da área ambiental e de alimentos tem conhecimento sobre os transgênicos, mas as informações sobre seus impactos ao ambiente e à saúde ainda são desconhecidas.

Embora, os participantes tenham obtido mais informações em veículos de comunicação, os mesmos consideram essas informações menos confiáveis do que as obtidas nas instituições de ensino. Isto aponta a importância do papel das instituições de ensino em compartilhar com a sociedade os conhecimentos produzidos na academia. Além disso, é fundamental que mais pesquisas sejam realizadas sobre os impactos dos transgênicos, porque seus consumidores desejam e tem o direito de saber se os impactos são positivos ou negativos.

\section{Referências}

ASIAN FOOD INFORMATION CENTRE. 2004. Transgenics. Disponível em: $<$ http://www.ific.org/research/upload/2004-Biotech-Consumer-Research.pdf,7/9/ 2004>. Acesso em: 07 set. 2015. 
BORÉM, A.; SANTOS, F.R. Entendendo a biotecnologia. Universidade Federal de Viçosa. Viçosa, MG, 2008.

CÉLERES. Infográfico: Benefícios Socioambientais da Biotecnologia nas Lavouras Brasileiras. Disponível em: $<$ http://www.celeres.com.br/pdf/Infografico estudo biotech 2011.pdf>. Acesso em: 12 jan. 2012.

CÉLERES. Relatório de Biotecnologia - Dezembro de 2011. Disponível em: $<$ http://www.celeres.com.br/1/RelBiotecBrasil 1103.pdf >. Acesso em: 10 jan. 2012.

CENTRO DE INTELIGÊNCIA DA SOJA - Cl Soja. Utilização do grão. Disponível em: <http://www.cisoja.com.br/index.php?p=utilizacao >. Acesso em: 25 maio 2012.

COLLI, W. Organismos transgênicos no Brasil: regular ou desregular? Revista USP, n. 89, p. 148-173, 2011.

COMISSÃO TÉCNICA NACIONAL DE BIOSSEGURANÇA - CTNBIO. Aprovações comerciais. Plantas. Disponível em: $<$ http://www.ctnbio.gov.br/index.php/content/view/12482.html>. Acesso em: 24 mai. 2012.

COMISSÃO TÉCNICA NACIONAL DE BIOSSEGURANÇA - CTNBIO. CTNBio. Disponível em: $<$ http://www.ctnbio.gov.br/index.php/content/view/2.html>. Acesso em: 18 ab. 2012.

COMISSÃO TÉCNICA NACIONAL DE BIOSSEGURANÇA - CTNBIO. CTNBio. Disponível em: $<$ http://www.ctnbio.gov.br/index.php/content/view/17002.html>. Acesso em: 06 mar. 2015.

FOOD INSIGHT: Your Nutrition and Food Safety Resource, 2006. Disponível em:<http://www.foodinsight.org/Food Biotechnology A Study of U S Consu mer Attitudinal Trends 2006>. Acesso em: 06 mar. 2014.

FURNIVAL, A.C.; PINHEIRO, S.M. A percepção pública da informação sobre os potenciais riscos dos transgênicos na cadeia alimentar. História, Ciências, Saúde, v.15, n.2, p.277-291, 2008.

GIULIANI, G.M. O dilema dos transgênicos. Estudos Sociedade e Agricultura, 15: 13-38, 2000.

GREENPEACE. Pesquisa de opinião pública sobre transgênicos. IBOPE, Nov./Dez. 2003. Disponível em: $<$ http://www.greenpeace.org.br/transgenicos/pdf/pesquisalBOPE 2003.pdf>. Acesso em: 18 abr. 2012. 
GREENPEACE. Transgênicos. Perigo para a agricultura e a biodiversidade. Disponível em: <http://www.greenpeace.org/brasil/pt/O-quefazemos/Transgenicos/>. Acesso em: 10 mai. 2012.

GRIFFITHS, A.J.F.; WESSLER, S.R.; LEWONTIN, R.C.; CARROLL, S.B. Introdução à Genética. 9a edição, Ed. Guanabara Koogan, Rio de Janeiro, 2008.

GUIVANT, J.S. Transgênicos e percepção pública da ciência no Brasil. Ambiente \& Sociedade, Vol. IX, n. 1, 2006.

NODARI, R.O.; GUERRA, M.P. Implicações dos transgênicos na sustentabilidade ambiental e agrícola. História, Ciências, Saúde, vol. VII, n. 2, p. 481-91, 2000.

NODARI, R.O.; GUERRA, M.P. Plantas transgênicas e seus produtos: impactos, riscos e segurança alimentar (Biossegurança de plantas transgênicas). Revista de Nutrição, v. 16, n. 1, p. 105-116, 2003.

ODA, L.M.; SOARES, B.E.C. Biotecnologia no Brasil. Aceitabilidade pública e desenvolvimento econômico. Parcerias Estratégicas, № 10. Mar. 2001. 